\title{
IKLAN KOMERSIAL MEDIA CETAK: TINJAUAN TEKS DAN KONTEKS
}

\author{
Moh. Masrukhi \\ moh_masruhi@yahoo.com \\ Sastra Arab Departemen Bahasa dan Sastra \\ Fakultas Ilmu Budaya Universitas Gadjah Mada Yogyakarta
}

\begin{abstract}
Advertising is the means the company to introduce, promote products, and sell them to the public. Print ads generally use verbal element of the display (text) and nonverbal elements (contexts). These two elements with sales messages conveyed to the reader or potential consumers. Therefore, the problem is how to link these elements to form a whole discourse in commercial advertising (IKOMES), especially in the print media in Egypt. What is the structure of these elements and how the meaning or message(s) contained in it, and how the meaning or message that contained therein. So, thereader can understand what the advertiser wishes. A number of research data is collected from various newspapers and magazines that published in Egyptwhich containelements of verbal and nonverbal as well as having elements as Leech concepts. Therefore, commercial advertisements containing text and context of the local culture and contain sales messages to the audience.The data were analyzed with advertising discourse by utilizing several theories simultaneously. The theories will be used are the theory of discourse, pragmatic theory, and the theory of semiotics. The results of the research that has been done is as for the message is delivered in IKOMES more through nonverbal elements because more interesting. Nevertheless in advertising, to explain the nonverbal elements, at least one verbal element must be displayed, namely al-khaththur-raīsi or headline.
\end{abstract}

Keywords: advertising, elements of verbal, nonverbal elements, text, context, and message.

$$
\begin{aligned}
& \text { ملخص } \\
& \text { الإعلان هو وسيلة الشركة لطرح وترويج المنتجات وبيعها للمجتمع. عموما استخدام الإعلانات المطبوعة يحتوى }
\end{aligned}
$$

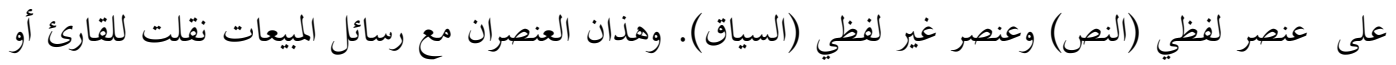

$$
\begin{aligned}
& \text { المستهلكين المحتملين. ولذلك، فإن المشكلة هي كيفية ربط هذه العناصر لتشكيل الخطاب كله في الإعلانات } \\
& \text { التجارية ، وخاصة في وسائل الإعلام المطبوعة في مصر. ما هو هيكل هذه العناصر وما المعنى أو الرسالة الواردة }
\end{aligned}
$$

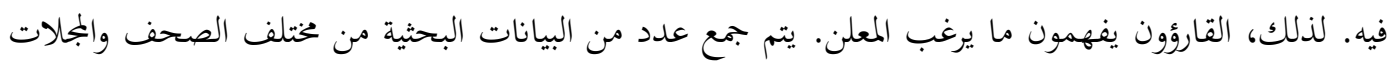

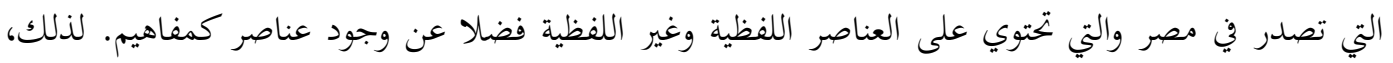

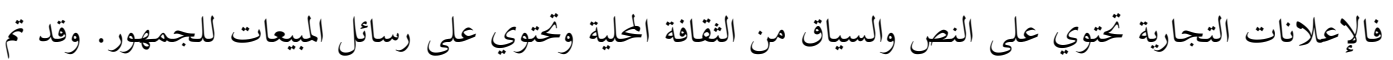

$$
\begin{aligned}
& \text { تحليل البيانات مع الخطاب الإعلاني من خلال الاستفادة من عدة نظريات في وقت واحد. وسوف تستخدم } \\
& \text { النظريات هي نظرية الخطاب، ونظرية واقعية، ونظرية السيميائية. نتائج البحث التي تم القيام به على النحو التالى : }
\end{aligned}
$$

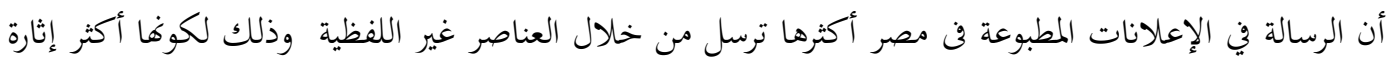




$$
\text { للاهتمام. ومع ذلك، ولشرح العناصر غير اللفظية في الإعلانات، يجب عرض العنصر اللفظي على الأقل عنصرا }
$$

\section{I.Pendahuluan}

Kehidupan masyarakat modern yang konsumtif seperti sekarang ini, memicu peningkatan produksi barang dan jasa (Masruhi, 2014:127). Produk-produk barang dan jasa terus membanjiri pasar domestik maupun pasar global yang mendorong terjadinya integrasi pasar internasional yang tak mungkin dihindarkan (Abdullah, 2003:103-104) oleh negara manapun. Akibatnya, saat ini sistem ekonomi semakin mengandalkan pasar.

Membanjirnya komoditas di pasar global memerlukan pemasaran atau penjualan. Oleh karena itu, saat ini berbagai bentuk usaha, dari usaha eceran hingga perusahaan multinasional mengandalkan iklan dan promosi. Iklan menjadi instrumen promosi yang sangat dikenal karena daya jangkaunya yang sangat luas. Iklan dapat tumbuh subur di mana-mana karena mampu berkompetisi dengan cepat di ekonomi pasar global (El Daly, 2011:2). Iklan menjadi sistem komunikasi dan informasi yang sangat penting, tidak saja bagi produsen, tetapi juga bagi konsumen yang digunakan untuk mengambil keputusan akan mambeli atau tidak (Morissan, 2010:2).

Alessandri (dalam Drewniany (ed.), 2008:36-37) mengatakan iklan (komersial) merupakan sarana untuk mengenalkan merek 'product identity' atau 'branding image' kepada khalayak. Tujuannya adalah untuk memberikan motifasi untuk menumbuhkan kesadaran dan mempengaruhi pasar 'marketing influence'. Pada akhirnya identitas atau merek tersebut dapat memenangkan pendapat publik identity leads to image sesuai dengan keinginan dan produksinya laku di pasar.

Penampilan iklan komersial (IKOMES) di media cetak terdiri atas verbal (teks) dan nonverbal (konteks). Kedua unsur tersebut kemudian terdistribusi pada elemen-elemen. Elemenelemen itulah yang menjadi penggerak dan pemberi ruh kepada IKOMES dan membentuk sebuah wacana iklan yang utuh (Masrukhi, 2014:128). Dalam iklan, unsur verbal (teks) dianggap lebih efsien karena tidak mengenal batasan ruang dan waktu (Keraf, 1991:18). Sementara unsur nonverbal yang berupa visual, seperti gambar atau ilustrasi, juga diyakini sangat penting karena memiliki pengaruh yang lebih kuat dalam iklan.

Bahasa dalam iklan seperti yang disebutkan para ahli sebagai 'langue' dan 'parole', 'signifier' dan 'signified' serta 'performance' dan 'competance' tidak lagi berlaku secara penuh. Sebab sebagaian besar bahasa IKOMES sekarang ini tidak memiliki hubungan secara linguistis dengan produk barang dan jasa yang diiklankan.

Fenomena kebahasaan semacam ini dapat dilihat pada ikan rokok di Indonesia, misalnya rokok Sampoerna Hijau dengan slogannya "Nggak Ada Loe Nggak Rame" atau rokok A Mild "Yang Lantang Suaranya akan Segera Tampil Ke Depan". Secara linguistik, antara verbal dengan produk yang ditampilkan tidak ada kaitannya sama sekali. Eksploitasi kebahasaan semacam ini, pada tampilan nonverbal juga menunjukkan kecenderungan yang sama, yaitu antara 
tanda verbal yang ditampilkan dengan produk barang yang diiklankan kadang tidak memiliki hubungan. Dengan demikian, apa sesungguhnya yang ingin disampaikan pengiklan melalui penanda verbal dan nonverbal tersebut?

Konteks iklan merupakan elemen yang mengaitkan kepada produk barang atau jasa yang diiklankan. Teks iklan merupakan tanda verbal yang bersamasama berfungsi untuk memperjelas konteks. Dengan menyatunya kedua unsur ini supaya makna dan pesan yang ingin disampaikan pengiklan dapat dipahami.

\section{II.Kerangka Teori}

\section{Iklan dan Wacana}

Iklan menurut orang awam adalah 'jualan' atau usaha menjual produk, barang atau jasa kepada masyarakat umum (Masrukhi, 2014:128). Ralph Alexander (dalam Morissan, 2010:17-18) mendefinisikan iklan sebagai "any paid of nonpersonal communication about an organization, product, service, or idea by an identified sposor" atau setiap bentuk komunikasi nonpersonal mengenai suatu organisasi, produk, servis, atau ide yang dibayar satu sponsor yang diketahui. Maksud kata 'dibayar' pada definisi tersebut kira-kira adalah ruang dan waktu bagi suatu pesan pada umumnya harus dibayar, sedangkan 'nonpersonal' maksudnya pemasangan iklan melibatkan media massa, seperti televisi, radio, ataupun koran dan majalah yang pada saat bersamaan mengirimkan pesan kepada sejumlah kelompok atau individu di berbagai tempat.

Definisi serupa dalam The Collins Concise Dictionary (dalam Cook, 2009:9) menyebutkan bahwa advertising is 'the promotion of goods or services for sale through impersonal media'. Dengan begitu, sifat nonpersonal atau impersonal media di sini maksudnya beriklan melalui media tersebut umumnya tidak ada kesempatan untuk mendapatkan umpan balik atau respon segera dari penerima pesan. Karena itu sebelum pesan iklan dikirimkan, pemasanng iklan harus betulbetul mempertimbangkan bagaimana penerima pesannya menginterpretasikan dan memberikan respon terhadap pesan yang dikirimkan.

Iklan juga dikatakan sebagai alat pemasaran yang persuasif untuk maksud menjual barang atau jasa kepada khalayak (Wright dalam Liliweri, 1992:17). Jadi, iklan adalah suatu usaha untuk memberikan informasi, meyakinkan atau membujuk orang banyak melalui bahasa dan disertai gambar ilustrasi agar calon konsumen menyukai, memilih, dan membeli barang yang ditawarkan melalui iklan (Masrukhi, 2014:128).

Dalam iklan menyatunya unsur verbal dan nonverbal seperti itu membentuk sebuah wacana dan wacana yang demikian menurut Samsuri (1988:1) merupakan wacana yang bersifat pragmatis. Oleh karena itu, iklan sebagai sebuah wacana seharusnya tidak dibicarakan terbatas hanya dari segi bahasa (teks), tetapi juga konteks. Kramsci dalam Octavianus (2006:280) menyebutkan: Discourse are more than just language, they are ways of being in the world, or forms of life that integrates word, act, values, beliefs, attitude, and social identities. Konteks sangat berperan sebagai pembentuk teks. Teks sendiri tanpa konteks tidak sepenuhnya dapat menampilkan makna dan pesan yang ingin disampaikan. Konteks ekstralingual atau fi dlau'il-maqām (Hasan, 2009:39) sangat dibutuhkan. Analisis wacana itu tidak hanya sekedar menjelaskan sistem tanda atau simbol (verbal) untuk mengungkapkan makna atau maksud penutur yang tersembunyi di balik sebuah tuturan (Wijana, 2009:118).

\section{Struktur, Tanda, dan Makna \\ a. Struktur Iklan}

Leech (1966:59) mengelompokkan unsur verbal dan nonverbal dalam iklan, khususnya media cetak, menjadi 5 elemen utama, yaitu: headline 'al-khaththur-ra' '̄si $(K R)$ ', body copy 'an-nashshul-i lāni (NI)', 
illustration 'at-tashwīr(Tsh)', signature line 'khaththut-tauqī' (KT), dan standing details 'khātimah (Kht)' (lihat juga Masrukhi, 2014:129-130). Dalam tampilannya elemen-elemen tersebut, baik unsur teks maupun konteks dalam IKOMES membentuk kesatuan yang utuh menjadi sebuah struktur iklan komersial yang memiliki tipe-tipe atau pola.Tipe struktur iklan yang paling komplit memiliki 5 elemen dan yang struktur iklan paling sederhana memiliki 2 elemen (Masrukhi, 2016:120). Setiap tipe memiliki beberapa struktur konstruksi atau susunan elemen pembentuk yang berbeda.Misalanya:

(a).Tipe A (5 elemen) variasi komposisinya adalah:

1. (KR), (NI), (Tsh), (KT), dan (Kht),

2. (KR), (Tsh), (KT), (NI), dan (Kht),

3. (KT), (KR), (NI), (Tsh), dan (Kht),

4. (KT), (KR), (Tsh), (NI), dan (Kht).

(b).Tipe D (2 elemen) variasi komposisinya adalah:

1. (KR)dan (Tsh),

2. (Tsh) dan (KT),

3. (KT) dan (Kht).

Begitu pula tipe-tipe struktur yang lain dan memiliki beberapa vaiasi komposisinya yang berbeda-beda (Masrukhi, 2016:256). Namun, semuanya tetap membentuk satu kesatuan wacana yang memiliki makna dan pesan yang utuh.

\section{b. Tanda: Semiotika}

Pada dasarnya semiotika sebagai induk semua kajian tentang makna tanda (sign). Referensi yang ada di dalamnya adalah tanda, ciri pembeda (peran), dan ramalan (makna) (Martinet, 2010:3). Di dalam semiotika atau semiologi dikaji bagaimana tanda (sign) dan cara tandatanda itu bekerja. Seseorang ketika berkomunikasi menggunakan tanda untuk mengirim makna tentang suatu objek, kemudian orang lain akan menginterpretasikan atau memaknai tanda yang disampaikan. Syaratnya, kedua belah pihak harus memiliki bahasa atau pengetahuan yang sama terhadap sistem tanda tersebut. Namun, pemaknaan di sini bukanlah konsep yang statis yang dapat ditemukan dalam kemasan pesan saja, tetapi pemaknaan merupakan proses aktif sehingga sangat mungkin sesuatu yang sama dapat berbeda maknanya pada waktu yang berbeda.

Hubungan antara tanda dengan representasi realitasnya lebih dikenal dengan hubungan antara penanda (tanda) dengan petanda (makna). Antara penanda dan petanda tidak ada korelasi satu-satu, melainkan bersifat arbitrer atau manasuka. Tanda sendiri ada yang ditemukan manusia dan ada tanda yang dibuat manusia. Melalui pengalaman, manusia menandai bahwa asap merupakan tanda adanya api dan tidak akan ada asap kalau tidak ada api. Ini yang disebut indeks (berkaitan) atau contiguity, yaitu asap sebagai indeks dari api (Fiske, 2007:69).

Penanda verbal (teks) dalam IKOMES misalnya dimanfaatkan pada elemen $A l$ Khaththur-Ra'īsi

Utama/verbal), (KR/Judul (NI/Badan Iklan), Khaththut-Tauqi (KT/Tanda Tangan), dan Khātimah (Kht/Penutup). Penanda nonverbal (gambar visual untuk mengarahkan kepada konteks) dimanfaatkan pada elemen Al-'UnwānurRa'̄̌si (UR/Judul Utama/Nonverbal), AtTashwir (Tsh, Gambar/llustrasi), dan khaththut-tauqī (KT/Tanda Tangan).

\section{c. Makna}

Hal penting dalam telaah wacana IKOMES adalah proses memaknai setiap tanda yang disampaikan oleh seseorang berdasarkan pengetahuan atau pengalaman yang sudah dimiliki (prinsip analogi). Pengalaman inilah yang kemudian dapat membangkitkan kembali pikirannya untuk mengasosiasikan dengan tanda lain sehingga ketika mengalami sesuatu yang sedang dihadapi dapat memaknai kembali sesai dengan pengalamannya (kontekstual). Selain itu, juga digunakan prinsip penafsiran lokal, yaitu dalam menginterpretasikan wacana dengan cara mencari kaitan atau konteks yang 
melingkupi wacana itu berada (Muyana, 2005:71-72).

Kajian tentang makna secara pragmatis tidak akan terlepas dari konteks karena bahasa itu benar-benar dipakai dalam berbagai fungsi di dalam masyarakat sebagaimana dinyatakan J. L. Austin (1962) dalam Sumarsono (2011:322) tentang tindak tutur (ilokusi dan perlokusi). Di samping itu, juga menyangkut aspekaspek yang lain, seperti implikatur (maksud atau pengertian), presuposisi (praanggapan), referensi (hal yang dirujuk), dan inferensi (kesimpulan).

\section{III.Pembahasan}

Analisis IKOMES sebagai sebuah wacana dalam tulisan ini bertujuan untuk menjabarkan unsur serta elemen wacana. Pembahasannya akan menyandarkan diri pada konsep struktur wacana van Dijk (1980). Struktur yang digagas van Dijk tersebut meliputi superstruktur, struktur mikro, dan struktur makro. Namun, dari ketiga konsep tersebut, kali ini, akan lebih difokuskan pada struktur makro dan supestruktur, sedangkan struktur mikro dijelaskan sekedar untuk mendukung pemaknaan kedua struktur yang lain. Hal ini dilakukan dengan pertimbangan bahwa strktur mikro pembicaraannya khusus terkait dengan masalah sintaksis (verbal) saja, sementara pemaknaan pesan dalam wacana IKOMES ini tidak hanya berorientasi pada unsur verbal saja melainkan juga berorientasi pada unsur nonverbal.

Berdasarkan tampilannya, IKOMES di bawah ini terdiri atas lima elemen pembentuk, yaitu al-khaththur-ra'issi (KR), at-tashwīr (Tsh), an-nashshul-i lāni (NI), khathtauqī (KT), khātimah (Kht), dan beberapa bagian elemen, seperti raq'ah 'splash', rāyah 'banner/flagger', syarch 'spot', dan at-taudlich 'caption' yang nantinya juga akan dibicarakan sekaligus bersamaan dengan pembicaraan yang sesuai dengan elemen-elemen atau bagian tersebut menjadi pembicaraannya. Misalnya, taudlīch'caption' akan dibicarakan pada elemen Tsh karena taudlīch 'caption' ini menjadi bagian elemen tersebut. Dengan memiliki elemenelemen seperti tersebut di atas, maka IKOMES merupakan iklan yang memiliki struktur lengkap sesuai dengan ancangan Leech, yaitu iklan yang memiliki lima elemen pembentuk wacana. Analisis unsurunsur pembangun wacana tersebut dapat diuraikan sebagai berikut:

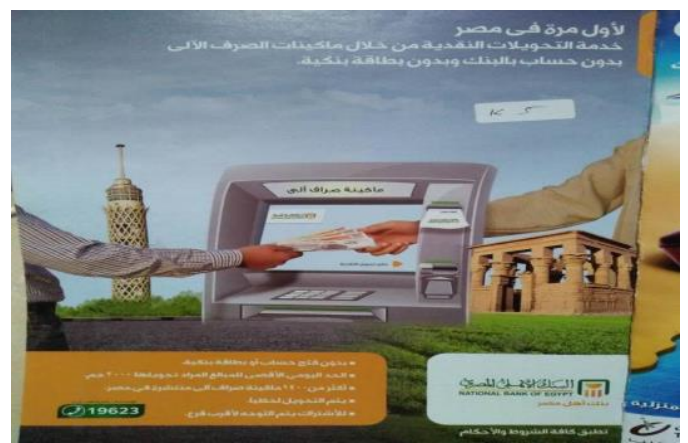

Gambar 1: 'Bank Nasional Mesir' (SKJ, 25/4/2013)

Contoh (gambar 1) di atas ini adalah IKOMES'Bank Nasional Mesir' yang memiliki lima elemen pembentuk atau tipe struktur yang paling lengkap. Elemenelemen yang membangun wacana iklan ini adalah: al-khaththur-raīsiy (KR, Judul), attashwir (Tsh, Ilustrasi/gambar), annashshul-i lāniy (NI/Badan Iklan), khaththut-tauqi $\bar{l}$ (KT/Tanda Tangan), khātimah (Kht/Penutup). Elemen-elemen tersebut dapat dicermati pada tabel di bawah.

\begin{tabular}{|c|l|l|}
\hline $\begin{array}{c}\text { No } \\
\cdot\end{array}$ & \multicolumn{1}{|c|}{ Iklan (1) } & $\begin{array}{c}\text { Posisi (V) dan } \\
\text { (NV) pada } \\
\text { elemen }\end{array}$ \\
\hline 1. & $\begin{array}{l}\text { [Li awwal } \\
\text { marrah fi Mashr] } \\
\text { 'Pertama di } \\
\text { Mesir' }\end{array}$ & KR \\
\hline 2. & $\begin{array}{l}\text { [Khidmat at- } \\
\text { tachwīlātin- } \\
\text { naqdiyyah min } \\
\text { khilāi } \\
\text { mākīnātish- } \\
\text { sharfil ālī bidūni } \\
\text { chisāb bil-bank }\end{array}$ & NI (pertama) \\
\hline
\end{tabular}




\begin{tabular}{|c|c|c|}
\hline & $\begin{array}{l}\text { wa bidūni } \\
\text { buthāqat } \\
\text { bankiyah] } \\
\text { 'Layanan setoran } \\
\text { tunai melalui } \\
\text { mesin ATM } \\
\text { tanpa rekening } \\
\text { atau buku } \\
\text { tabungan Bank' }\end{array}$ & \\
\hline 3. & 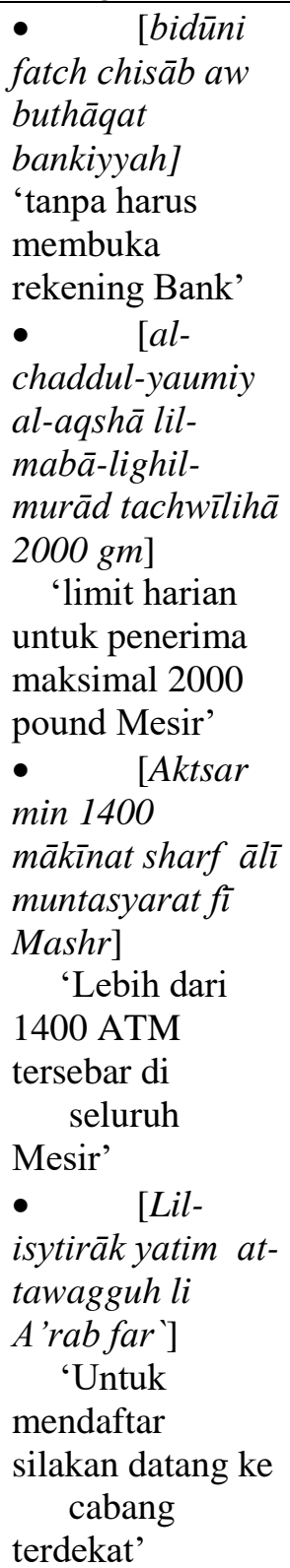 & $\begin{array}{l}N I \quad \text { (kedua) } \\
\text { berupa } \\
\text { keterangan } \\
\text { produk }\end{array}$ \\
\hline 4. & $\begin{array}{l}\text { - ikon } \\
\text { mesin ATM, } \\
\text { landscape Mesir, } \\
\text { dan logo Bank. }\end{array}$ & $\begin{array}{l}\begin{array}{l}T s h, \\
\text { (NV) }\end{array} \\
\text { dan }\end{array}$ \\
\hline
\end{tabular}

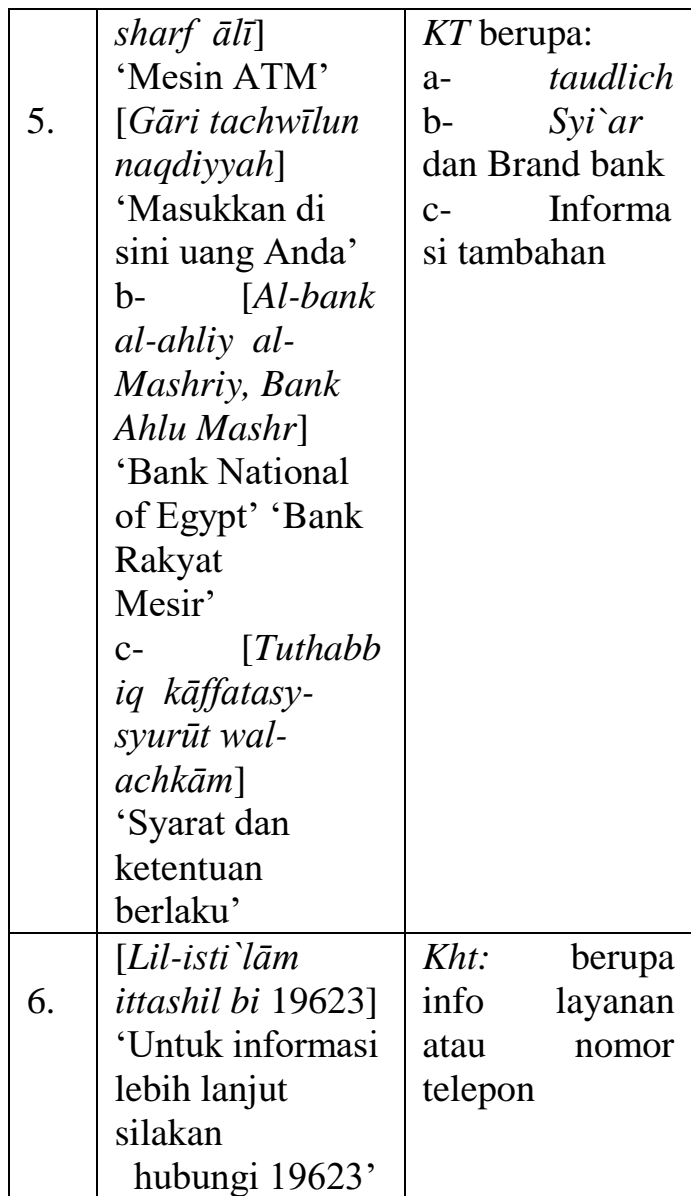

Tabel 1: Elemen-elemen wacana iklan.

Dari tabel di atas dapat diperhatikan bahwa unsur (V) hadir dan menempati semua elemen, yaitu pada elemen $K R, N I$, $K T$, dan $K h t$. Sementara unsur (NV) hanya menempati elemen $T s h$, dan $K T$. Variasi yang terdapat pada iklan tipe ini adanya unsur verbal yang agak panjang yang menjadi penjelas $K R$. Elemen ini diletakkan di bawah elemen $K R$ dengan tampilan jenis huruf yang sama, tetapi ukurannya lebih kecil dari $K R$.

Keterkaitan unsur (V) dan (NV) dalam iklan di atas dapat diperhatikan pada penggunaan kata fi Mashr 'di Mesir' dan muntasyarat fi Mashr 'tersebar di berbagai tempat di Mesir' (V) berkorelasi dengan gambar-gambar menara (mengindikasikan Mesir bagian Utara) dan bangunan candi (mengindikasikan Mesir bagian Selatan) (NV); kata Khidmat at-tachwìlāt bidūni buthāqat bankiyah 'layanan setoran tanpa 
buku tabungan' (V) berkorelasi dengan dua tangan yang memberikan dan menerima uang di tengah-tengan mesin ATM (secara langsung) (NV); dan kata mākinātish-sharf 'mesin ATM' (V) berkorelasi dengan gambar mesin ATM (NV) sendiri. Keterkiatan antar unsur-unsur pembentuk iklan inilah yang kemudian menjadikan iklan tersebut menjadi sebuah rangkaian tuturan menjadi sebuah wacana yang runtut dan bermakna dan sekaligus mengandung pesan-pesan penjualan yang ingin disampaikan oleh pengiklan.

Wacana yang dihasilkan iklan merupakan proses komunikasi yang bertautan dan saling berhubungan satu sama lain. Hal ini dinyatakan oleh Luxemburg (1984:100) bahwa wacana yang demikian memiliki tahapan-tahapan, yaitu mulai dari awal, tengah, sampai akhir. Tahapan-tahapan komunikasi itu juga akhirnya menentukan struktur wacana sehingga wacana juga memiliki bagianbagian. Bagian awal merupakan pembuka wacana, bagian tengah adalah tubuh wacana yang berfungsi sebagai penjelas isi wacana atau hal-hal utama yang ingin disampaikan, dan bagian akhir merupakan penutup, yaitu berfungsi sebagai penanda akhir wacana.

\section{Pembuka}

Elemen pertama atau pembuka dalam iklan adalah al-khaththur-raīsì atau judul. Sifat judul headline ini adalah penting dalam iklan karena merupakan pengait hook dengan elemen berikutnya (Lowe, 1996) dalam Santoso (2007:22) sekaligus pengait dengan unsur nonverbal. Peran hook ini di dalam iklan adalah untuk menciptakan suspense atau kejutan dan sekaligus menarik perhatian calon konsumen (eye cacher) (Bathia, 1992:196). Sebagai pembuka, hook atau judul harus membuat mitra tuturnya 'terangsang', 'tergiur' dan 'ingin tahu' apa selanjutnya dan bagaimana. Jadi, pengait ini tugasnya adalah untuk 'merangsang' benak mitra tutur. Hook tidak harus lengkap dan memang pada umumnya singkat sesuai dengan situasi, orisinil, menarik, dan memikat khalayak. Dengan demikian mitra tutur atau calon konsumen dapat dengan cepat memahami pesannya (unsur verbal dan nonverbal) secara sekilas. Misalnya:

"(1) "أول مرة فن مصر"

Li awwal marrah fi Mashr

'Pertama di Mesir'

Klausa "Li awwal marrah fi Mashr"di atas telah dipilih oleh pengiklan sebagai judul atau al-khaththur-ra'issi atau KR iklannya. Bentuk kalimat (nominal) tersebut di atas jika diperhatikan kiranya sudah memenuhi kriteria seperti disebutkan di atas, yaitu singkat, tidak lengkap, menimbulkan pertanyaan dan merangsang keingintahuan calon konsumen untuk mengetahui apa sebetulnya yang ingin disampaikan pengiklan kepada calon konsumen. Begitu pula dari sudut pandang hook atau pengait antara judul dengan unsur nonverbal dalam iklan juga sudah memenuhi, yaitu perhatian calon konsumen yang semula tertuju pada bentuk (teks) verbal tersebut. Pembaca pasti akan bertanya-tanya: "Apa yang pertam terjadi di Mesir? Pelayanan apa? dan sebagainya. Hal ini tentu tidak akan mereka temukan jawabannya jika hanya melihat pada judul tersebut. Karena belum menemukan jawabannya itulah kemudian pembaca beralih ke elemen berikutnya, yaitu ke bagian visual yang ditampilkan. Dengan beralih ke bagian visualnya, maka pembaca akan tahu, tetapi mungkin belum paham, apa sebenarnya yang dimaksud dengan tuturan ' $\mathrm{Li}$ awwal marrah fi Mashr'di atas. Hal itu bisa diperhatikan dalam contoh iklan berikut.

Dengan memperhatikan iklan tersebut secara urut dan menyeluruh, dari awal sampai akhir, maka kemudian pembaca atau calon konsumen akan dapat memahami bahwa yang dimaksud pengiklan. Misalnya, frasa nomina (V) 'layanan setoran tunai' adalah 'pelayanan bank untuk menerima tabungan tanpa harus membawa buku tabungan, tersebar di banyak tempat di Mesir, baik di belahan selatan maupun di utara. Bentuk verbal 
tersebut kemudian disertai bentuk-bentuk visual (NV) yang saling terkait antara keduanya. Pemertalian antara verbal dan nonverbal atau simbolisasi semacam inilah yang menjadikan IKOMES menjadi menarik. Bagi pembaca lain yang belum mengenal Mesir dari visual tersebut juga akan tahu bahwa di Mesir memiliki peradaban yang tinggi, dan sebagainya.

Unsur pengisi pada pembuka dapat juga berupa unsur nonverbal. Dengan unsur nonverbal adalah ketika pengiklan ingin menonjolkan sesuatu, seperti hasil produk ataupun merek (brand name) karena ingin mengenalkan produk barunya kepada khalayak, dan sebagainya. Hal ini tampaknya menjadi kecenderungan copywriter atau pendesain dalam pembuatan iklannya. Dari itu, maka posisi judul ini mungkin saja ditampilkan pada posisi elemen lain, seperti khaththut-tauq ${ }^{`}$ (KT) atau signature line, yaitu berupa simbol perusahaan/produsen brand name, nama produk (verbal), logo, flagger atau rāyah, dan splash atau raq ah (verbal atau nonverbal), sebagaimana dapat diperhatikan pada iklan semen di bawah ini.

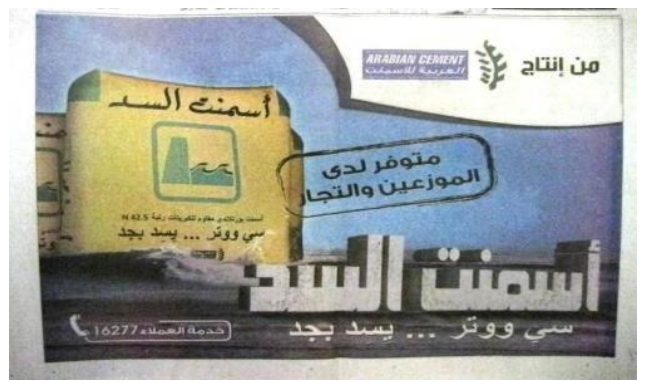

Gambar 2: 'Asmant As-Sad'

Pada sisi kanan atas iklan (2) terdapat logo berupa 'tulang daun' (nonverbal) dan nama produsen semen Asmant As-Sad, yaitu Arabian Cement (verbal). Dalam iklan, elemen $K T$ ini umumnya terletak di tengah atau di akhir iklan, seperti dinyatakan oleh G. Leech (1966:59) bahwa elemen $K R$ dan $K T$ sering menyatu dalam satu display, yaitu sederet dengan posisi $K R$. Di samping itu, ada elemen lain yang juga dapat menempati posisi sejajar dengan $K R$, tetapi tidak banyak atau jarang, yaitu elemen khätimah atau standing details, yaitu berupa teks verbal yang menunjukkan nomor telepon yang bisa dihubungai oleh pelanggan, yaitu khidmatul- 'umalā' 16277 'Layanan pelanggan (silakan telpon ke) 16277'. Elemen ini posisinya diletakkan di bagian sisi kiri elemen KR: Asmant As-Sad sī water... yisid bigid 'Semen As-Sad, air laut ... dibendung dengan kuat'.

\section{Tubuh Iklan}

Istilah yang sering dipakai dalam wacana periklanan tubuh iklan ini adalah bodycopy atau badan teks. Tubuh iklan merupakan bagian pokok iklan yang berfungsi sebagai sarana pembangkit minat calon konsumen. Leech (1966:59) sebagai the main part of the advertising message, often divided into various section under subheads. 'Bagian inti pesan iklan, seringkali dibagi menjadi beberapa bagian di bawah sub-judul'. Dalam tubuh inilah tempat menyelesaikan pertanyaan, pemberitahuan, pernyataan atau masalah yang sengaja dibuat oleh copywriter dalam KR sehingga calon konsumen dapat tertarik dan berminat menggunakan atau memiliki barang yang ditawarkan.

Tubuh iklan terdiri atas rangkaian kalimat yang menjelaskan berbagai hal yang berkaitan dengan keunggulan-keunggulan produk dan menerangkan alasan-alasan mengapa orang tetap membeli dan menggunakan produk/jasa yang ditawarkan. Dalam tubuh ini juga dikembangkan pesan-pesan yang membuat produknya dapat dipercaya oleh konsumen. Elemen yang menempati bagian tubuh ini biasanya disebut bodycopy atau annashshul-i lāni (NI), yaitu berupa teks verbal. Teks yang disampaikan dapat panjang dan pendek, tergantung pada jenis barang/jasa yang ditawarkan. Barang yang sederhana dijelaskan secara ringkas dan sebaliknya barang yang kompleks dan canggih diberikan penjelasan yang lebih panjang dan proporsional. Misalnya, dapat 
diperhatikan teks yang ada dalam elemen NI berikut.

$$
\begin{aligned}
& \text { "خدمة التحويلات النقدية من خلال ماكينات الصرف الآل }
\end{aligned}
$$

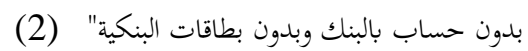

Khidmat at-tachwīlātin-naqdiyyah min khilāli mākinātish-sharfil ālì bidūni chisāb bil-bank wa bidūni buthāqat bankiyah]

'Layanan setoran tunai melalui mesin ATM tanpa rekening atau buku tabungan Bank'

"اسمنت السد . . . سي ووتر يسد بحد" (3) (3)

asmant as-sad ... yisid bigid

'Semen As-Sad ... air laut ... dibendung sangat kuat'

Jika diperhatikan kalimat-kalimat (2) dan (3) di atas kata-kata yang terasa kuat dan menyentuh adalah: Khidmat attachwīlātin-naqdiyyah min khilāli mākīnātish-sharfilālì 'Layanan setoran tunai melalui mesin ATM' pada contoh (2) dan kalimat yisid bigid 'membendung dengan sangat kuat' pada contoh (3). Kalimat-kalimat itu harus mempunyai dampak dan meninggalkan kesan yang mendalam kepada calon konsumen. Untuk menguraikan kelebihan-kelebihan produk yang diiklankan, pengiklan atau copywriter dianjurkan memanfaatkan kata-kata sifat atau ajektiva, penggunaan gambargambar/diagram bermanfaat pula untuk memperkuat pesan iklan. Dengan demikian uraian tubuh iklan ini dapat membentuk dan menghasilkan prilaku, janji-janji, keyakinan, ilusi terhadap barang-barang yang diiklankan, dan rasa penasaran jika tidak membeli produk yang diiklankan (Pajnik, 2002:279).

Pada bagian tubuh ini unsur atau elemen pengisinya dapat berupa unsur verbal dan nonverbal. Dari unsur verbal, NI berupa teks yang menjelaskan produk dan keterangan-keterangan lain tentang produk. Di samping itu, seringkali diikuti elemen $K T$ berupacontoh produk, logo perusahaan (nonverbal), dan harga produk.

\section{Bagian Penutup Wacana}

Pada bagian akhir atau penutup iklan umumnya memuat hal-hal yang terkait dengan keterangan tambahan, seperti layanan konsumen, pusat informasi, bagaimana konsumen dapat menanyakan dan mencari tahu lebih lanjut terkait dengan produk yang ditawarkan, di mana konsumen dapat membeli produk seperti yang diiklankan, dan sebagainya. Dengan begitu, umumnya perusahaan pengiklan kemudian memberikan alamat kantor atau distributor, nomor tilpun yang bisa dihubungi, atau web yang memuat penjelasan produk secara lengkap tentang produk tersebut. Bagian ini biasanya berupa teks verbal yang diletakkan di bawah dengan font huruf yang lebih dibandingkan dengan yang lainnya.

Dari segi elemen pengisi, bagian penutup ini dapat berupa Kht dan $K T$. Dengan elemen Kht berupa unsur verbal, sedangkan dengan elemen $K T$, dapat berupa unsur verbal, seperti nomor telepon, alamat, website, dan slogan dan unsur nonverbal berupa logo perusahaan, logo Facebook, ikon telepon, dan sebagainya. Elemen tersebut dapat diperhatikan pada bagian paling bawah iklan 1 dan 2 di atas.

"لاشتراك يتم التوجه لأقرب فرع 19623" (4)

Lil-isytirāk yatim at-tawagguh li a'rab far` 19623

'Untuk mendaftar silakan datang ke cabang terdekat'

disertai dengan logo Bank Al-Ahly Al-

Mashry (nonverbal)

"خدمة العملاء 16277" (5 (5) (16277)

khidmat al- 'umalā' 16277

'Layanan konsumen 16277'.

disertai dengan ikon telepon (nonverbal)

Contoh iklan-iklan di atas sengaja dibuat dan ditampilkan kepada khlayak untuk maksud menjual produk supaya disukai dan dibeli oleh masyarakat. Pembahasan mengenai unsur pembentuk iklan dan keterkaitan keduanya, struktur elemenelemen yang membentuk wacana sudah dijelaskan secara keseluruhan, maka akhirnya bentuk wacana tersebut dapat 
dipahami pesan-pesan yang terkandung di dalamnya sebagai berikut.

Iklan (contoh 2\#), Mesir merupakan negara yang memiliki peradaban tinggi dan sudah dikenal dunia. Hasil peradaban itu berupa peninggalan-peninggalan seperti candi dan tempat-tempat ibadah masyarakat Mesir Kuna.Peningalanpeninggalan ini umumnya terdapat di Mesir bagian selatan. Di samping itu, Mesir juga satu Negara di Benua Afrika yang mengikuti perkembangan kehidupan modern, seperti banyaknya instansi perbankan untuk menunjang perekonomian negeri, telekomunikasi seluler, dan sebagainya. Hal ini ditandai dengan bangunan menara Telkom, adanya mesinmesin layanan tunai mandiri (ATM) yang tersebar di seluruh wilayah Mesir, baik di bagian selatan maupun di bagian utara negeri yang semuanya merupakan bentukbentuk identitas dunia terkini atau dunia modern.

Perkembangan perbankan pada kehidupan modern ini juga terus mengalami kemajuan, yaitu adanya mesinmesin ATM. Mesin ATM yang sekarang ini ada tidak hanya untuk mengambil uang secara tunai saja, tetapi juga menyediakan ATM untuk menyetor uang tunai. Dengan adanya ATM semacam ini para nasabah tidak harus pergi ke bank pada jam-jam kerja saja di siang hari, tetapi mereka juga dapat menyetor atau menabung uangnya di luar jam kantor ke bank-bank nasabah tersebut.

Kemudahan-kemudahan bertransaksi inilah yang sekarang disediakan oleh bank, salah satunya adalah Bank Al-Ahly Al-Mashry. Dengan menabung di bank ini nasabah tidak perlu repot mengurus segala macam urusan, seperti nomor rekening, buku tabungan, antri yang panjang, dan sebagainya. Nasabah cukup datang ke ATM khusus ini dan masukkan langsung uangnya di sana, di mana pun dan kapan pun.

Iklan (contoh \#2) di atas Asmant Assad 'Semen Bendungan' merupakan brand semen yang diproduksi Arabian Cement. Pemilihan khat pada contoh di atas dapat diperhatikan setidak-tidaknya ada dua jenis khat, yaitu Asmant As-sad yang terdapat pada sak (tempat semen) dan Asmant Assad yang ditanam di pinggir pantai. Yang pertama, khat pada sak atau tempat semen adalah variasi dari khat Diwani. Khat Diwani, gaya-gaya tertentu, biasanya untuk motif-motif kaligrafi dan figural (AlFaruqi, 2001:404). Karena itu, bentuknya tampak lentur, meliuk-liuk, dan tidak kaku. Namun, sebaliknya bentuk huruf yang digunakan untuk Asmant As-sad yang diletakkan di pinggir pantai, mengisyaratkan sebuah bangunan yang sangat besar, kuat, dan tampak sangat kokoh, tidak gampang goyah meski dihantam ombak lautan yang sangat besar. Font yang dipilih untuk kata-kata ini adalah variasi khat $3 D$ square kufiyang digunakan untuk menandai makna kuat, kokoh, tegas, dan sebagainya. Bentuk fontnya semacam balok-balok yang sangat kuat dan tidak mudah goyah. Hal ini mungkin untuk memberikan persepsi kepada pengguna bahwa semen As-Sad adalah semen yang lentur (mudah dalam pengerjaan), tetapi kuat dan kokoh hasilnya.

Di Mesir bangunan gedung perkantoran atau tempat tingal sangat jarang ditemukan seperti yang ada di Indonesia. Bangunan rumah tinggal di sana kebanyakan berbentuk apartemen bertingkat. Bangunan apartemen biasanya sekurang-kuranya memiliki empat atau lima tingkat. Sebagaimana diketahui, di Mesir (Selatan) juga terdapat sebuah bendungan raksasa yang sangat terkenal, yaitu Bendungan Aswan. Bangunan bertingkat dan bendungan adalah bangunan yang memerlukan bahan-bahan yang kuat dan berkualitas. Semen yang kuat untuk menopangnya karena jika tidak menggunakan bahan-bahan yang berkualitas, maka bangunan tersebut tentu akan cepat roboh atau bahkan rusak.

Jadi, dengan pemilihan bentuk huruf atau khat dalam iklan tersebut menunjukkan keterkaitan dengan lingkungannya, yaitu bila Anda akan 
membangun apartemen atau bangunanbangunan lainnya, gunakan saja semen Assad. Sement As-sad mudah dalam pengerjaannya, lentur, dan tidak keras. Namun, Anda akan dapat melihat hasilnya jika bangunan Anda sudah jadi. Bangunan Anda akan kuat, kokoh, dan sekokoh bendungan raksasa Aswan.

\section{IV.Kesimpulan}

IKOMES dibangun atas dua unsur, yaitu unsur verbal (teks) dan nonverbal beserta konteksnya. Kedua unsur tersebut disertai elemen-elemennya masing-masing dan membentuk struktur dan variasi komposisinya yang berbeda-beda. Bersatunya dua unsur tersebut dalam iklan komersial menjadi sebuah komunikasi yang utuh, runtut, dan dapat dipahami. Komunikasi inilah yang membentuk wacana periklanan yang memiliki ruh atau daya tarik sehingga dapat memikat dan menarik perhatian. Pada kedua unsur tesebut pesan-pesan penjualan disandarkan agar dapat dimaknai dan dipahami pemirsa atau pembaca. Proses pemaknaannya memanfaatkan prinsip-prinsip penafsiran analogi dan prinsip penafsiran lokal.Artinya, unsur teks (verbal) dipadukan dengan unsur nonverbal (konteks) yang melingkupi wacana IKOMES kemudian dikaitkan dengan kondisi budaya masyarakat setempat. Dari situlah makna dan pesan penjualan dapat diperoleh sesuai dengan pengalaman dan pengetahuan pembacanya.

\section{Daftar Pustaka}

Abdullah, Irwan, dan Sjafri Sairin. 2003. Viewing Yogyakarta Through Billboard Media dalam Urban Culture Research, Vol. 1. Yogyakarta: UCRC Yogyakarta Subcenter.

Agustrjanto. 2006. Copywriting: Seni Mengasah Kreativitas dan Memahami Bahasa Iklan. Bandung: Remaja Rosdakarya.
Badawi, El Said, Martin Hinds. 2009. A Dictionary of Egyptian Arabic. Beirut: Librairie du Liban.

Bathia, T.K. 1987. English in Advertising: Multiple Mixing and Media. Journal of World Englishes, Vol. 6, No. I (33-48).

Cook, Guy. The Discourse of Advertising. Second Edition. London and New York: Routledge.

Drewniany, Bonnie L, A. Jerome Jewler. 2008. Creative Strategy in Advertising. Ninth Edition. United State: Wadsworth Cengage Learning

Jalal, Aiman Sa'id. 2006. Lughatu al-I'lan at-Tijariy, Dirasah lima Nasyara fi 'Amai 1952 wa 2002 fi Jaridah Akhbar al-Yaum. Kairo: Maktabah Al Adab.

Keraf, Gorys. 2001. Diksi dan Gaya Bahasa; Seri Retorika. Jakarta: Gramedia Pustaka Utama.

Liliweri, Alo. 1992. Dasar-dasaar Komunikasi Periklanan. Bandung: Citra Aditya Bakti.

Leech, Geofrey N. 1966. English in Advertising: A Linguiuistic Study of Advrtiseising in Great Britain. First Published.London: Longman.

Van Luxemburg, Jan dkk. 1984. Pengantar Ilmu Sastra. Diterjemahkan Dick Hartoko. Jakarta: PT Gramedia.

Masrukhi, Moh. 2014. Structure of Commercial Advertising in Egypt Printed Media.Jurnal CMES. Vol. VIII, No. 2. Surakarta: FSSR UNS.

Masrukhi, Moh. 2016. "Unsur Verbal dan Nonverbal dalam Iklan Komersial Media Cetak Mesir: Analisis Wacana”. Disertasi.Yogyakarta: Universitas Gadjah Mada.

Morissan. 2010. Periklanan, Komunikasi Pemasaran Terpadu. Cetakan I. Jakarta: Kencana Prenada Media Group. 
Mulyawan, I Wayan. 2010. Hipersemiotika Periklanan: Analisis Praktis. Denpasar: Udayana Unibersity Press.

Martinet, Jeanne. 2010. Semiologi: Kajian Teori Saussuran Antara Semiologi Komunikasi dan Semiologi Signifikasi. Stephanus Aswar Herwinarko (Penerjemah). Yohyakarta: Jalasutra

Piliang, Yasraf Amir. 2003. Hipersemiotika Tafsir Cultural Studies Atas Matinya Makna.Yogyakarta: Percetakan Jalasutra.

Santosa, Wahyudi Joko, 2007. "Wacana Iklan Komersial Berbahasa Indonesia di Televisi" Disertasi. Yogyakarta: Universitas Gadjah Mada.

Samsuri.1987/1988.Analisis Wacana. Malang: IKIP Malang.

Sumarsosno.2011. Sosiolinguistik. Yogyakarta: Pustaka Pelajar dan Sabda.

Va Dijk, Teun. A. 1980. Macrostructures An Interdisciplinary Study of Global

Structuresin Discourse, Interaction, and Cognition. Hillsdale, New Jersey: Lawrence Erlbaum Associates, Publishers. 1985. Handbook of Discourse Analysis: Discourse and Dialogue. Volume 3. Orlando: Academic Press, Inc.

Wijana, I Dewa Putu Wijana. 1991. "Language of Advertising." Laporan Penelitian. Yogyakarta: Universitas Gadjah Mada. 1999. Semantik. Yogyakarta: Fakultas Sastra Universitas Gadjah Mada.

\section{Artikel Internet:}

El-Daly, Hosney M. 2011. Towards an Understanding of the Discourse of Advertising:
Review of Research with Special Reference to the Egyptian Media. African Nebula, Issue 3, June 2011.

Gully, Adrian. 2006. The Discourse Of Arabic Advertising:Preliminary Investigations.Journal of Arabic and Islamic Studies 1 (1996-97). Diunduh 14/03/2012.

Pajnik, Mojca and Lesjak-Tušek. 2002. Observing Discourses of Advertising: $\quad$ Mobitel's Interpellation of Potential Consumers. Journal of Communication Inquiry 26:3 (July 2002): 277-299. Sage Publications. Diunduh 19/10/2011. 